\title{
Sanctions against scientists threaten progress
}

\section{SIR - Several European countries, including France, the Netherlands and Sweden, are now routinely refusing work visas and study positions in the physical sciences to Iranian scientists and students. This is in response to UN resolution 1737 , imposing sanctions on Iran for failing to halt uranium enrichment, and reflects international concern about the potential proliferation of nuclear- threat to scientific progress. \\ Bengt Gustafsson Department of Physics and Astronomy, Uppsala University, Box 515, 75120 Uppsala, Sweden e-mail: bengt.gustafsson@fysast.uu.se \\ Measures urgently required to prevent multiple submissions} weapons technology. The result has been blanket discrimination simply on the basis of nationality.

Similar national-security policies against academics operate in the Middle East. The permit criteria used by Israel's security services for Palestinian postgraduate students are so restrictive that they effectively prohibit entry. Israeli universities have protested, in a letter sent to the defence ministry, that these policies constitute "a gross and harmful intervention by military elements in purely academic considerations" (see http:// go.nature.com/iFljgR).

The International Council for Science (ICSU) affirms, in its principle of universality in science, that all scientists should have the opportunity to participate in legitimate scientific activities. ICSU's committee on freedom and responsibility in the conduct of science, which I chair, continuously monitors breaches of this principle. We have recently called for the scientific community to commit to opposing all such discrimination (see http:// go.nature.com/2UmM5M).

Academic institutions should have the responsibility and freedom to select students and staff without political or military interference. If selected individuals are refused entry or a work visa after security screening, the reasons should be made clear to that person.

International collaboration and openness in science education and research are essential for meeting pressing global challenges. Systematic discrimination against scientists based on nationality is a serious

SIR - A recent experience leads me to believe that defiance of rules against simultaneous submission of papers to different journals may be growing more widespread.

In a thorough review of a submitted paper (not for this journal), I pointed out that the study itself and the organization of the manuscript were below standard; I offered substantive constructive comments and recommended reconsideration after major revision. When the revised manuscript arrived, I made further suggestions for improving its scientific quality.

At this point, and while the manuscript was technically still under consideration by the journal in question, I noticed in had been published in a different peer-reviewed journal offering rapid publication. Evidently, the authors had submitted the manuscript to the other journal, either simultaneously or after having received the reviewers' comments, without withdrawing it from the first. They had even incorporated some of the comments from my original review.

Cases of duplicate submission are disconcerting for journals and for the scientific community. They seriously violate the principle of disseminating scientific findings with professionalism and integrity. The practice is in breach of the authors' contract to withhold a routine online search that it submission of their manuscript to other journals until the editors have made a formal decision not to publish it.

As the pressure to publish new results rapidly increases and competition becomes ever more intense, editors must define strict reinforcing measures to prevent such violations.

Goudarz Molaei The Connecticut Agricultural Experiment Station, 123 Huntington Street, New Haven, Connecticut 06504, USA e-mail:goudarz.molaei@ct.gov

Nature journals forbid duplicate submission: http://go.nature.com/ dthpdU

\section{Caution with claims that a species has been rediscovered}

SIR - We welcome the recent announcement by the conservation partnership BirdLife International that they have launched a "global bid to try to confirm the continued existence of 47 species of bird that have not been seen for up to 184 years" (see http://go.nature. $\mathrm{com} / 6 \mathrm{Hc} 2 \mathrm{Cn}$ ). But there are pitfalls, as the recent history of 'rediscoveries' has shown.

One of the species on BirdLife's target list is the ivory-billed woodpecker (Campephilus principalis), a bird that was prematurely alleged to have been rediscovered in 2005 . This seemingly improbable reappearance provoked intense debate within the scientific community about the veracity of claimed sightings and, more generally, about what represents sufficient proof of continued existence (or extinction).

Accusations of 'faith-based' ornithology resulted, increasing scepticism among politicians and policy-makers that conservation organizations are often too willing to put public relations before scientific rigour.

Many rediscoveries in the developing world are made by individuals or organizations from Europe or the United States, or are a direct result of Western-backed expeditions or initiatives. This wrongly reinforces the impression that only Western scientists are competent to find and save threatened species. In addition, high-profile rediscoveries can create an unexpected imperative for immediate action by hardpressed national conservation organizations.

The international conservation community often seems to want it both ways, being unwilling to declare a species extinct but enthusiastically proclaiming the rediscovery of an 'extinct' species. This ambiguity is understandable - high biogeographic uncertainty can be generated both by the IUCN Red List requirements for 'exhaustive surveys' before a species is officially declared extinct, and by frequent taxonomic revisions that propel rarely seen subspecies to full species status. Rediscoveries are only meaningful if backed up by a self-sustaining population. Otherwise, conservationists are merely engaged in the sad task of documenting the prolonged demise of yet another species.

The genuine rediscovery of 'lost' species is a newsworthy event that helps bolster the pioneering, field-based credentials of conservation and draws attention to new sites worthy of increased protection. The combination of technology and improved access makes finding these species easier than ever. The real challenge is how to present rediscoveries to the public in a way that reflects their conservation significance and that will best encourage the support of future conservation efforts.

Richard J. Ladle, Paul Jepson Oxford University Centre for the Environment, Oxford OX13QY, UK e-mail: richard.ladle@ouce.ox.ac.uk Steve Jennings Oxfam GB, South Asia RMC (Delhi), New Delhi, India Ana C. M. Malhado Department of Agricultural and Environmental Engineering, Federal University of Viçosa, Viçosa, Minas Gerais, Brazil 